\title{
Knowledge Management for Rural Industries using Cloud Computing
}

\author{
Narendra S. Katikar, Rahul B. Hiremath, Rakesh yadav
}

\begin{abstract}
About more than two decades ago, the practice of Knowledge Management (KM) was started. Also their importance was understood by the many growing and developed organizations. Now it becomes as an importantly integral and inherent component of any business units. Knowledge management (KM) is actually the process of creating, sharing, using and managing the knowledge and information of any organisation. Actually to achieving organisational objectives, it refers to a multidisciplinary approach. This is by making the best use of knowledge. KM efforts focus on organisational many of the objectives. Some of these are like improved performance, competitive advantage, innovation, the sharing of lessons learned, integration and continuous improvement of the organisation.
\end{abstract}

"Rural industries" refers to the small-scale activities that took place in communities where the dominant economic pursuits revolved around agriculture or natural product extraction. Such industry supported these activities and processed their output.

Cloud computing is defined as "the practice of using a network of remote servers hosted on the Internet to store, manage, and process data, rather than a local server/personal computer."

Because of Information and Computer Technologies (ICT), it is possible to put many innovative fruitful ideas into KM practices. In reality this expresses the new trends in KM. This also justifies that, various newly developed technologies have impacted on, how the knowledge is managed? One of advanced, most predominant technology is Cloud Computing, ofcourse within the ICT. The way IT services are provisioned, it has significantly impacted. The rural industries can now get the advantage of such hosted services for major IT activities. This is nothing but KM through the means of Cloud Computing. Before the advent of Cloud Computing, earlier it was beyond their budget.

Knowledge Management (KM) is moving towards new paradigm in which organizations are expected to change how knowledge are created and managed, by adopting new tools such as cloud computing. Cloud computing has started to be one of the new opportunities for rural industries in the current business landscape.

The cloud environment application will be discussed in framework model form. This is with reference to various strategies of the knowledge management along with their combined adaptability. This is for catering the futuristic need in this predominant area.

Keywords: Cloud Computing (CC), Knowledge Management (KM), Knowledge Management System (KMS), Rural Industries (RI).

Revised Manuscript Received on September 10, 2019.

Narendra S. Katikar, Mechanical Engg. Dept., Walchand Institute of Technology,Solapur, Maharashtra, India.

(Email: narendraskatikar@gmail.com)

Rahul B Hiremath, SCMHRD, SIU Pune, Maharashtra, India.

(Email: rahulhiremath @ gmail.com)

Rakesh Yadav, Assitant Professor, Faculty of Management Studies, SCMHRD, SIU Pune, Maharashtra, India.

(Email: rakesh_yadav@scmhrd.edu)

\section{INTRODUCTION}

Most of the organizations have begun to realize and acknowledge the existence and importance of knowledge management (KM) and its ability to improve organizational performance and ensuring sustainability in the competitive marketplace. Knowledge from different resources has become the strategic weapon for organizations to be different from the competitors.

In relation to this recognition of the value of knowledge, organizations have started to strategize their own KM initiatives. It is covering many activities. These are such as i) finding ii) mapping iii)gathering iv)filtering information v)developing new knowledge, and converting personal knowledge resources. This wills also adding value to information further transform into knowledge. "KM is a dynamic process that can be seen by two related perspectives that are business and technology" (Aksoy \& Algawiaz, 2014). Therefore, in order to achieve successful KM implementation in organizations, KM should be aligned with business objectives as well as technology, which is changing rapidly. This notion is stated by Sveiby (1997), where he sees KM approaches are focused on three dimensions; i.e. People, Process and Technology.

The rural industries are directly/indirectly contributing to the Indian economy. Thus to strengthen it, a advanced toolstechnology is mandatorily applied with serious concentration. Whatsoever the development occurs due to advanced technology for urban industries, actually simultaneously it must be implemented for rural industries.

In the same study by Sveiby (1997), it can be noted that technology plays a big role in supporting KM implementation in organizations. Therefore, the needs of tools and technology as a platform for KM are detrimental as these tools and technology not only facilitate KM processes, but also determine KM success in fulfilling the operational and strategic needs and requirements of the organizations. The rapid changes in technology nowadays have led to the emergent of many new tools and platforms. One of the pertinent new technologies is cloud computing, whereby cloud computing based platform for $\mathrm{KM}$ implementations in organizations has also emerged (Gunadham, 2015). Cloud storage application is given significant attention due its high availability \& easy accessibility especially for the knowledge workers. Gartner (2009) described cloud computing as "a service that offering IT capability with the huge expansion power to different external stakeholders such as servicing customers through the Internet services".

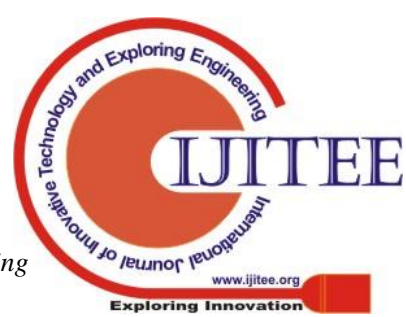




\section{LITERATURE REVIEW}

\section{A. Knowledge Management (KM) and Knowledge Management System (KMS)}

The KM concepts was started more than two decades ago (Rafiq, Bashar, \& Shaikh, 2014). Many researchers have different views \& perspectives regarding knowledge as well as KM, thus leads to no standardized definition of both terms as they are depending on the context of use. The knowledge definition may be-a fluid mixture of various facts like contextual information, framed experience, values, experts' insight \& grounded intuition. This further provides an approach environment and framework for evaluating and it's incorporating a new experience and all kinds of information (Davenport \& Prusak, 1998). This understanding is supported with the research done by Alavi \& Leidner (1999).Also knowledge is defined as a process of information through the mind of individual. Undoubtedly, knowledge needs to be shared within organization to reap its value. For managing knowledge the key challenge is nothing but the ability to integrate \& apply specific knowledge, and this is of organizational all members. This also create extendedly sustain the competitive advantage (Gunadham, 2015).

Generally, the KM purpose is also to make knowledge usable as a whole in organization. And also to share it among an individual's (Bimol, Saikia, \& Devi, 2014). Despite the various definitions of KM, it can basically be defined as a set of spectrum; it includes the knowledge creation, knowledge acquisition, knowledge representation, knowledge transfer and application of knowledge. In other words, KM assists organizations to organize and transfer important and valuable information for decision making, planning and analysis to achieve the organisations' goals and targets. According to the various definitions, it can be concluded that KM concentrates on 'doing the right thing' where instead of known fact 'doing things right' (Moshari, 2013).

Actually KMS fulfills the user's requirements in the form of knowledge source along with the variety information in the $\mathrm{CC}$ environment. And this is with a web browser. It curtails the expense on hardware maintenance along with various licenses of softwares. These are affecting majorly on the organization.(Anupan, Nilsook, and Wannapiroon, 2015)

Therefore, to have an effective knowledge sharing, collaboration and information delivery environment, organizations need to consider the adoption of Knowledge Management Systems (KMS). KMS includes hardware, software, people and environment of an organization. This supports the knowledge creation, knowledge transfer and it's dissemination among the organization's employees. Thus it is assisting in establishing a valuable knowledge ecosystem in organization. When an employee's knowledgesharing behavior is measured, it has a strong relationship with organizational support, \& thus can contribute to the achievement of the organizational objectives King\& Marks(2008).

\section{B. Cloud Computing (CC)}

Now CC is an upcoming application platform. It has drawn more attention from many industries and academic, research fields. The term cloud computing first came in to existence in 1997. It only became prevalent just recently. 'Cloud' is considerably metaphorical, normally refers to a massive pool of various resources. This includes hardware as well as software that are usable, and it is accessible easily over the Internet.

The first one of the objective of $\mathrm{CC}$ is to share data and services among organizational users and that to be in IT environment. In addition, IT barriers of innovation can reduce with assistance of cloud computing. For instance, Facebook and YouTube can be considered as the main ITservices innovators, which most of these IT-services are made possible by adopting cloud computing. Therefore, a newer practical concept of computing based on that to be the network access is ultimately cloud computing. In other words, it is a technology which allows sharing of resources including hardware, software and information over a network.

An emerging technology ' $\mathrm{CC}$ ' referred as a new paradigm. (Lyer and Henderson, 2010; Zhang et al., 2010). Whereas some researcher believes that it's not really a brand new concept, as it already uses various computing technologies by traditional means (Dillon et al., 2010). On the other side, the most wanted computing models are expected to influence on the way as many enterprises approaches IT-related services. Based on the clients computing requirements, Cloud service models are classified. It represents different layers of the cloud computing architecture. Some of these are likeinfrastructure as a service, platform as a service and software as a service. The cloud deployment models are classified according to type of exclusive cloud services and non-exclusive cloud services method of providing to the clients. These are as follows: a) public cloud b) private cloud c) hybrid cloud and d) community clouds (Mell and Grance, 2010). Actually Cloud-based end-user services are increasing day by day rigorously and finding their own way into various business practices such as e-mail or office applications etc. It offering new opportunities and capabilities and equally creating new challenges for stakeholders.

\section{Accessing KM through Cloud Computing (CC)}

Conventionally, KM processes such as knowledge creation and knowledge transfer have carried through various traditional methods. Some of these are discussion, face to face communications, counseling, staff development, and job rotation (Singh, 2013). These traditional approaches may become inadequate \& ineffective, as organizations expand virtually \& globally. Cloud computing helps in overcoming the organizational various boundary limitations. This is by allowing the various automatic update as well further access regularly to the newest as well the most appropriate \& relevant knowledge in real-time basis to enhance the provision of services and open access management. 
Cloud computing has been identified as one of the new approaches in KM and has a great influence in the development of KMS. The CC manages data/information and knowledge with a provision of a central location. Further providing a platform to available them as per demand, for example like other available computing resources. The some of the beneficial advantages of CC integrating with KMS are, to cutting down the costs, adopting newly developed practices, and exploring various new defined business models.

Current literatures such as Gunadham (2015) pointed out the link for improving organizational performance, between $\mathrm{KM}$ and cloud computing. Numerous researches have also indicated on KM improvements, those are with the use of cloud computing technologies. Thus it formed a new dimension for KM implementation. Thus, cloud-based KM will help to minimize the financial expenditure associated with KM implementation as it does not require organizations to buy and maintain the required equipment, infrastructure and applications. This notion is also supported by Liao, Chih and Fu (2011) who indicate that cloud computing contributes in achieving KM's main objectives in a more effective and efficient manner.

\section{KM ADOPTION IN CLOUD COMPUTING}

ASince the emergence of the concept of KM through cloud computing, several related researches \& works were undertaken to study the different perspectives of KM in the cloud. Here few of the works related to $\mathrm{KM}$ in cloud computing platform like Chow (2007) concluded in using cloud as the storage platform, this application can help in management and employee satisfaction. In the cloud environment the users will definitely have a variety kind of skills set. This is for knowledge collection, it's process and present the business knowledge (Delic \& Riley, 2009). Where as Abdullah, Eri and Talib (2011)focused that KMS model can be implemented by using KM functionality and through networked computer. In order to ensure that KMS and cloud computing can be used effectively. Organizational learning can be supported by using knowledge sharing through cloud computing which could result in more positive performance of the organization. Thus study mentioned that a number of positive contributions can be attained in the application of Cloud Computing in KMS domain. Some are like as improved knowledge sharing and better organization of knowledge. A promising ICT approach i.e. of CC will improve the way about ICT as a service as perceive by people and businesses. Cloud environment provides organizations the possibility to access the required organizational information from anywhere. Cloud has a great possibility and optimized capability for providing KM and it's services. Further it can be used extensively for various areas of business. Actually it should be seen that, developing countries can prefer such kinds of models and it's best practices which are adopted by other government institutions. This is by utilizing CC technology and it will achieve similar kinds \& levels of success.

A. Challenges on KM Implementation in Cloud Computing improving the quality of the operations, inventory

Although $\mathrm{KM}$ in cloud computing is perceived as a way forward for KM, many organizations are still facing some challenges in adopting this approach. All these challenges need to be considered and addressed during the implementation stage to ensure the success of KM adoption through cloud computing. Below are the relevant challenges obtained from the literature and it is synthesized into three categories: Change Management, Lack of Trust, Data Leakage and Security.

\section{KNOWLEDGE MANAGEMENT SYSTEM}

\section{A. Use of a scalable KMS benefits are:}

- With the sharing of information throughout enterprise will improve teamwork and further it simplify integration of office document along with outlook synchronization

It delivers the publish content which carries static content and social networking

- For distinct enterprise information, it contains personalized pages and used for personalization also.

- Required content search is easy, where the documents are part of it and further can generate forms and workflows.

- In development of web parts there is inclusion of data integration and customization additionally its personalization

- Here single user interface is facilitate.

B. In managing knowledge assets potential challenges may be faced by clients

A vast number of unclassified data, large data volume is required to be integrated into a well single platform.

There process harmony may be inadequate. This enforce in hosting various tools for the different platforms.

Here sometimes due to lack of efficient search engine, results in more time consuming process for searching relevant information/content.

In certain cases for aid in solving business problems, there is an ineffective communication channel.

Here for users, centralized governance policies are absent for convenient systems adoption.

It is seen that problem with organizational guideline's reluctance to change and adopt.

It is observed that increased costs along with their scalability.

\section{Use of a scalable KMS benefits are:}

In various cases the online software can be alternative for the replacement of conventional content sharing methods. This is to ensure and confirm the smooth transition to a cloud based system.

Here to ensure platform or application support there is an enterprise application support team.

For data migration to cloud, there is designing a transition model. In that a standardized set of frameworks along with template may be done. 
In this gradual content transfer can be there from different various data sources to an online environment.

It can be enhance reusability establishment of Centralized asset library.

\section{CLOUD BASED KNOWLEDGE MANAGEMENT}

It is observed that there are many recent advancements in internet \& it's related technologies. It's got widespread popularity among many fields. The cloud technology is used to aid knowledge activities like sharing and other. The fundamental advantage of this is, that can be utilized throughout organizations. The need of time i.e. to keep up with technological developments, the organizations required to reevaluate as well is to be modernizing their $\mathrm{KM}$ strategies. The supervision \& control over content is complicated this is because of a wide range of information, knowledge and content of an organization. Also it has higher license costs. The only effective solution is KMS to fulfill various requirements of an organizations. After successfully transition into the cloud based KMS, an organization experiences the following benefits (Abouzar Sadeghzadeh, \& et al., 2014).

- Use of a single content management system reduces licensing expenses

- Transition to CC technology reduced ownership charges.

- Enhanced efficiency as well cooperation throughout enterprises via a unified system

- $\quad$ improved flexibility and scalability reduces risks.

- due to centralization, there is a consolidation of worldwide user profiles along with security improvement.

- There can be navigation as well branding consistency with a singular KM tool instead the use of multiple KM tools.

- There can be training in a centralized way, improves induction further confirms the system is full potentially enhanced.

The details of the framework are by each layer as follow:

\section{A. Infrastructure as a Service (IaaS)}

As per the organizations requirement, this system enables to utilize the servers along with all devices, entire network and importantly storage disks. A virtualization software technology is used. It consist servers as physical resources. This allows IaaS providers to present any clients with practically unlimited instances of any location servers. For upgradation of their applications versions, it is not needed to procure physical IT resources, companies use IaaS.

\section{B. Platform as a Service (PaaS)}

It is cloud hosted an applications platform which is developed using tools. It can be easily accessed and operated through a any web browser. This PaaS layer is well placed on the infrastructure layer's virtual machines. Further this is carrying without possessing specific expertise and it maintain web based applications.

\section{Software as a Service (SaaS)}

Here there is no need to develop tools like email, customer relationship management etc. which are either to be exclusively cloud based. Also these are accessible to web users or organizations on a paid basis, can be possible at anytime / anywhere basis. Organizational services can be charged periodically like monthly or as per their usage. There employees also affect on KMS to the greater extent. It will add greatly to organizational knowledge quantity through in house group's interaction. It can utilize the large knowledge repository which was created with the organization's great assets.

\section{Knowledge as a service (KaaS)}

This can be access from any location without any constraint, the specific and required knowledge at any instance of time. To ensure core competency, this service type uses strategic tool, cloud computing. Because of this service, the requirement about to recruit expert personnel will get considerably cut down. It also reduces various risks which are originating from human error. Now for almost all organizations, risk management and the ability to utilize knowledge along with expertise are become the mandatory part of organizational prioritize strategies. This is especially for small size as well newly established companies. At the outset, KaaS is a combination of organizational systems and knowledge based processes. Further this is also enabling $\mathrm{KM}$ at organizational level.

\section{RURAL INDUSTRY \& RESULTS}

The real India lives in its villages. In India $73 \%$ population lives in the rural areas that is in villages along with considerably tiny. India still breathes in villages, proves with the fact that more than 700 million of population is reside in about 6.5 lakhs villages.

For more than 60 years the real rural India has been ignored. The cloud technology will definitely bring the revolutionary change which is required to fill the gap and bridge the divided rural India and Urban India. Actually it will improve the rural economy of India to the greater extent. The principal only one of the source of income of India by default is agriculture. Thus need of time that the development of the ICT is basically to be focused and work out for the Indian agriculture sector.

Cloud computing is expressing a new class network based computing, to be place over the internet. This platform hides the complexity along with the details of user's underlying infrastructure. This is with applications with a provision of a very simple graphical user friendly interface.

It is being seen that through a dramatic change, latest technological development has happened almost in every field and as to be in agriculture also. Among the same CC technology impacted very positively not only on agriculture sector but also on its related services provided for users (Rakesh \& Mili Patel, 2013).

In recent years about in every sector of the developing nations, there are many new ICT technologies are being implemented. The principal \& main sources of income of developing countries are nothing but from the agriculture only. So, the ICT development is basically need to be 
favored majorly on this agricultural sector. But there is one of the primary drawbacks, considerable investment cost for the required ICT infrastructure and it's repair \& maintenance. For this result, the main objective for the IT experts is to find a speedy, efficient, most reliable, user friendly tool. But actually ICT tool is also to be cheaper. This paper is focusing the concept of an ICT tool implementing with these features. In real time $\mathrm{CC}$ will maintain a huge, updated, well customized \& the secured data base. And this is with requirement like instantaneous connectivity and it to be a reasonable investment cost. That Cloud Computing is new and advanced, efficient application ICT domain. The user uses the services like data access, real time computation, data storage. This is to without constraint of knowing the physical location and configuration of the system. There is always need to improve the overall economic condition of developing countries. For the same by default way is to improve the Indian agricultural sector. The most possible way to achieve is through the successful ICT tool implementation blending with Cloud Computing technology.

\section{A. Advantages of Cloud Computing for rural India}

- Cloud computing especially is more attractive for rural India due to its slow start-up cost.

- $\quad$ Ease of management-There will be no concerns for procuring licenses, air-conditions for data centers. The purchasing of additional hardware is not required.

- It can easily increase the user number along with locations with the affordable cost.

- Device can be a either of choice eg. desktop, computer, smart phone solar powered touch pad and with a added advantage of location independence.

- In India BSNL broadband project becomes the game changer for rural India, as it provides better data connectivity throughout the nation.

\section{B. Cloud usage in the Rural India-Rural Industries}

Actually the Cloud allows IT to implement even into smallest part of India. It creates access to the available information to the roots side and poorest to give them a real quality life. This can be done with knowledge empowerment through cloud connected devises like laptop, mobiles etc. In fact the Cloud services makes affordable \& accessible at a considerably a low cost. This can come to know from the example - Banks, Tele-medicine E-learning, Commodity /stock exchanges, Indian agricultural information, KYC \& credit bureaus, Citizen interface portals, etc.

Thus India will be definitely benefited due to Cloud usage in Rural area of India, following are the facts-

- $\quad$ Actually this Cloud system has potential to drive down costs predominantly of many systems, for example medical care, e-Governance, education, and other Government initiatives of computerization.

- The Cloud will definitely fills the great gap between rich urban and poor rural India perfectly. Thus revolutionarily gives the same level of playing field to all rural and urban Indians.

- Very importantly the Cloud enables English language speaking illiterate Indians to join the knowledge revolution. This will participate aggressively in governance and become a part of nations bright. This is just by facilitating them to interact on the internet/web in the various Indian regional language of their own choice normally may be with mother tongue.

Thus Cloud Computing paradigm can be used as an efficient tool for promoting the development of rural Industries. The services \& schemes provided by the government will become more reachable and fruitful than earlier. It will provide the overall development of rural people along with it provides huge opportunities from business point of view. The strategic move of adoption of cloud will make Information Technology easier \& cheaper to use. Also it will be widely open to access by mass population. Cloud Computing could help in bridging digital the gap between rural and urban India ( Sale,2016).

The cloud computing concept derived emergent of cloud storage application. Further it's popularity is also rapidly increasing day by day. It cab be seen some of the prominent examples among the popular cloud storage wide application in the market are Google Drive,OneDrive Box,Dropbox, etc.

It is seen that cloud computing is a revolution that could resolve KM problems in many organizations along with rural industries. The collaboration \& relation between both areas is new strategy. That offers new paradigm of gathering, redistributing knowledge with cloud-based enterprise applications. This assists in improving organizational performance. KM can be accessed by individual knowledge workers through the cloud platform anywhere \& anytime needed within the collaboration.

It can summarized that $\mathrm{KM}$ in cloud computing provides many advantageous features like more flexibility, greater scalability, lower costs, ease of use, increased security and also facilitate disaster recovery. To gain competitive advantage and indirectly enhance organizational performance of an organizations help of facility of cloud computing. Even though it can also be observed that the KM implementation of through cloud computing in rural industries is still really in a infancy stage.

In rural industries/areas, in real time CC technology usage has really a great chance in the India's overall development Definitely an effective $\mathrm{CC}$ implementation is encouraging the enthuasim of agricultural sector to the greater extent. Actually today Cloud Computing eliminates the need as a commercial infrastructure like maintaining costlier computing hardware, IT software, IT infrastructure, staff, various recourses and their respective O\&M. In CC networks there is an access to a configurable networks shared pool, storage, web servers, applications, IT service \& other important computing resources. In era of $\mathrm{CC}$ technology, in real environmental applications are very much helpful, like for centralized the agricultural related data bank (Farmers Weather, Soil-related, Research, Crop, fertilizers, pesticide information, Marketing and many more) in the cloud. 
Thus cloud computing technique actually delivers the agriculture-based knowledge and natural resources management also. This knowledge is straight away goes to the consumers, which are in a small towns/villages (in shops) and also in a wider region. This will drastically modify the total supply chain. Currently this is mainly under the control of large companies. Now it can change into a more direct \& shorter chain network among the producers and consumers. Thus CC technology, revolutionarily applicable for agriculture growth and its improvement. This confirms food safety, accelerate GDP of the nation. Further it circulate information and knowledge related to agriculture etc. to across the nation.

\section{CONCLUSION}

The KM is moving towards new phases whereby the organizations are expected to change the approach to creation of knowledge and it's management by adopting emerging advanced tools; known as cloud computing. It can be observed that cloud based KM will help rural industries in India in sharing resources and knowledge in a faster, reliable and more cost effective manner. This approach will help the organization to gain benefits and vast opportunities for enhancing the services to the customers or stakeholder. At the same time, this approach will also reduce costs and other technology complexity and improving workload optimization. Cloud computing also promotes employee satisfaction along with delivering better knowledge representation and management.

To attain the benefits mentioned above, rural industries of India need to have Government support. Also it should have their own proactive attitudes and start to adopt KM in cloud computing. Cloud computing has now begun to transform the way systems are built along with it's services delivered. It further providing with an opportunity to extend their impacts effectively. In addition, organization needs to needs to get the benefits of cloud computing in knowledge management because as this goes a long way in curtailing drastically the difficulties faced in the traditional KMS.

ICT are actually transforming all human activities, which includes agriculture and allied industries. As ICT is a most powerful and productive system, it can greatly accelerate economic and social development in rural areas of India. This new age technology $(\mathrm{CC}+\mathrm{KM})$ is helping for rural India to live a better life. In real time Cloud Computing along with KM can be helpful for the rural industries rather rural development in terms of rural population. And this is by overcoming the huge costs incurred for the infrastructure as well the required software. Thus it is concluded that $(\mathrm{CC}+\mathrm{KM})$ can be lead rural India development and also the economic growth of nation. And it leads to curtailing the price, will definitely create a world without a poverty.

\section{ACKNOWLEDGMENT}

I acknowledge Dr. Rahul Hiremath for his valuable guidance and kind support..

\section{REFERENCES}

1. T Aksoy, M. S., \& Algawiaz, D. (2014). Knowledge Management in the Cloud: Benefits and Risks.
International Journal of Computer Applications Technology and Research Volume, 3(11), 718- 720.

2. Alavi, M., \& Leidner, D. E. (1999). Knowledge management systems: issues, challenges, and benefits, Communications of the AIS, 1(7), 1-37.

3. Delic, K. A., \& Riley, J. A. (2009). Enterprise knowledge clouds: next generation $\mathrm{km}$ systems?Proceedings - International Conference on Information, Process, and Knowledge Management, eKNOW 2009, 49-53.

4. Gunadham, T. (2015). Potential of Cloud Storage Application as Knowledge Management System, International Journal of Innovation, Management and Technology, 6(2), 153-157.

5. King, W. R., \& Marks, P. V. (2008). Motivating knowledge sharing through a knowledge management system. Omega, 36(1), 131-146.

6. Moshari, J. (2013). Knowledge Management Issues in Malaysian Organizations: the Perceptions of Leaders. Journal of Knowledge Management, Economics and Information Technology, III(5), 1- 13.

7. Singh, J. (2013). Practicing Knowledge Management System. International Journal of Information, Business and Management, 5(4), 209-230.

8. Jake Gardner, Benefits of Cloud Computing, http://www.logicworks.net/blog/2012/10/the-benefits-ofcloud-computing. [Cited: March 10, 2011.]

9. Dr C. Chandramouli, Registrar General \& Census Commissioner, India. censusindia.gov.in/2011-provresults/india/Rural_Urban_2011.pdf.

10. Madanmohan Rao., Internet growth, impacts and success, yourstory.com/2015/02/internet-india-2018.

11. International Journal of Computer Applications Technology and Research Volume 3- Issue 11, 718 720, 2014, ISSN: 2319-8656

12. Mehmet Sabih ,Danah Algawiaz(1987), Knowledge Management in the Cloud: Benefits and Risks , CS Fischer - Journal of Social History,

13. Nirvikar Singh(2012), "ICTs and Rural Development in India”,International Journal of Information Technology and Knowledge Management, Volume 6, No. 1, pp. 98100

14. Kamna Choubisa(2012), Cloud Computing \& Rural Development, International Journal of Information Technology and Knowledge Management, Volume 6, No. 1, pp. 98-100

15. Abouzar Sadeghzadeh, Maryam Haghshenas, Mojtaba Nassiriyar, Roghayeh Shahbazi (2014), Adoption of Cloud based Knowledge Management, International Journal of Engineering and Innovative Technology (IJEIT) Volume 3, Issue 11

16. Nabilah Mahmud, Sulfeeza Mohd Drus (2017), A review of knowledge management implementation through cloud computing in Malaysia, Proceedings of the 6th International Conference on Computing and Informatics, (pp 621-627)

17. Musa, Shittu, Ahmadu Bello, Zaria (2015), Knowledge Management $(\mathrm{Km})$ In the Age of Cloud Computing (CC): Benefit and Challenges, National Seminar/Workshop Organised by Nigerian Library Association Abuja Chapter in Collaboration with University of Abuja, ,1st - 5th September, 2015

18. Meenu dave, Mikku Dave, Y S Shisodiya (2013), Cloud computing and Knowledge management as a service: A collaborative approach to Harness \& Manage the Plethora of Knowledge, BIJIT- BVICAM's International Journal of Information Technology 
19. Anuchit Anupan, Prachyanun Nilsook, and Panita Wannapiroon (2015), A Framework for a Knowledge Management System in a Cloud Computing Environment Using a Knowledge Engineering Approach, International Journal of Knowledge Engineering, Vol. 1, No. 2

20. Yazn Alshamaila , Savvas Papagiannidis, and Feng $\mathrm{Li}(2013)$, Cloud computing adoption by SMEs in the north east of England A multi-perspective framework, Journal of Enterprise Information Management,Vol. 26 No. 3, pp. 250-275

21. Rakesh Patel, Mili. Patel (2013), Application of Cloud Computing in Agricultural Development of Rural India, (IJCSIT) International Journal of Computer Science and Information Technologies, Vol. 4 (6), 922-926

22. Mahesh Arun Sale (2016), Cloud Computing For Rural India, International Journal for Research in Applied Science \& Engineering Technology (IJRASET), Volume 4 Issue $\mathrm{V}$

23. Abdullah, R., Eri, Z. D., \& Talib, A. M. (2011). A model of knowledge management system for facilitating knowledge as a service (KaaS) in cloud computing environment. 2011 International Conference on Research and Innovation in Information Systems, ICRIIS'11, 2016.

24. Aksoy, M. S., \& Algawiaz, D. (2014). Knowledge Management in the Cloud: Benefits and Risks. International Journal of Computer Applications Technology and Research Volume, 3(11), 718-720.

25. Alavi, M., \& Leidner, D. E. (1999). Knowledge management systems: issues, challenges, and benefits, Communications of the AIS, 1(7), 1-37.

26. Bimol S., Saikia M., \& Devi L. P. (2014), Achieving knowledge management through Cloud Computing: A case in higher education. 2014 International Conference on Computing for Sustainable Global Development (INDIACom), 222-227.

27. Chow, H.K., (2007), An RFID based knowledge management systems - An intelligent approach for managing logistics processes. In proceedings of the 5th IEEE International Conference on Industrial Informatics (INDIN), Hong Kong, 287-292.

28. Davenport, \& Prusak, L. (1998). Working Knowledge: How Organizations Manage What They Know. Knowledge Creation Diffusion Utilization, 309.

29. Delic, K. A., \& Riley, J. A. (2009). Enterprise knowledge clouds: next generation $\mathrm{km}$ systems? Proceedings - International Conference on Information, Process, and Knowledge Management, eKNOW 2009, 49-53.

30. Gartner. (2009). Gartner Says Worldwide Cloud Services Revenue Will Grow 21.3 Percent in 2009.

31. Gunadham, T. (2015). Potential of Cloud Storage Application as Knowledge Management System., International Journal of Innovation, Management and Technology, 6(2), 153-157.

32. King, W. R., \& Marks, P. V. (2008). Motivating knowledge sharing through a knowledge management system. Omega, 36(1), 131-146.

33. Liao, C. N., Chih, I. L., \& Fu, Y. K. (2011). Cloud computing: A conceptual framework for knowledge management system. Human Systems Management, 30(3), 137-143.

34. Moshari, J. (2013). Knowledge Management Issues in Malaysian Organizations: the Perceptions of Leaders. Journal of Knowledge Management, Economics and Information Technology, III(5), 1- 13.

35. Rafiq, M., Bashar, A., \& Shaikh, A. (2014). Innovative trends in knowledge Management: A cloud computing perspective. Proceeding of the First Middle East
Conference on Global Business, Economics, Finance and Banking, (October 2014), 10-12.

36. Singh, J. (2013). Practicing Knowledge Management System. International Journal of Information, Business and Management, 5(4), 209-230.

37. Sveiby, K., 1997, The New Organizational Wealth: Managing and Measuring Knowledge-based Assets, Berrett-Koehler Publishers, San Francisco, CA.

38. Dillon, T., Chen, W. and Chang, E. (2010), "Advanced information networking and applications (AINA)", 24th IEEE International Conference, 20-23 April 2010

39. Leimeister, S., Riedl, C., Bo"hm, M. and Krcmar, H. (2010), "The business perspective of cloud computing: actors, roles, and value networks", Proceedings of 18th European Conference on Information Systems ECIS 2010, Pretoria, South Africa, June 7-9

40. Lyer, B. and Henderson, J. (2010), "Preparing for the future: understanding the seven capabilities of cloud computing", Management Information Systems Quarterly Executive, Vol. 9 No. 2, pp. 117-131.

41. Mell, P. and Grance, T. (2010), "The NIST definition of cloud computing", available at www. newinnovationsguide.com/NIST_Cloud_Definition. pdf (accessed April 5, 2013).

42. Zhang, Q., Cheng, L. and Boutaba, R. (2010), "Cloud computing: state-of-the-art and research challenges", Journal of Internet Services and Applications, Vol. 1 No. 1, pp. 7-18.

\section{AUTHORS PROFILE}

Prof. Narendra S. Katikar, B.E. (Prod.Engg.) M.E.(Prod. Engg.), MBA(HR), Assistant Professor in Mech. Engg. in Walchand Institute of Technology, Solapur, India

Dr. Rahul B. Hiremath, B. E. (Mechanical), M Tech. (Mechanical), Ph.D. IISc., Banglore. Assistan Professor at Management Studies at Symbiosis International (Deemed University). SCMHRD, India. 